\section{EDIFICIO DE OFICINAS DEL MONTE DE PIEDAD $Y$ CAJA DE AHORROS DE SEVILLA-ESPAÑA}

Eleuterio Población Knappe, Arquitecto

$145-109$

\section{SINOPSIS}

La característica esencial de la nueva sede del Monte de Piedad y Caja de Ahorros de Sevilla, levantada sobre un solar en forma de "L» y afectada en el transcurso del proyecto y construcción por sucesivos cambios de Ordenanzas, armoniza con la arquitectura circundante, respetando sus características tradicionales.

La edificación, de siete plantas sobre rasante y dos sótanos, patentiza su distinta misión privada y de cara al público a través de los volúmenes, formas y diferentes tratamientos exteriores, presentando una especial atención a su funcionalidad de acuerdo con el programa inicial planteado por la entidad.

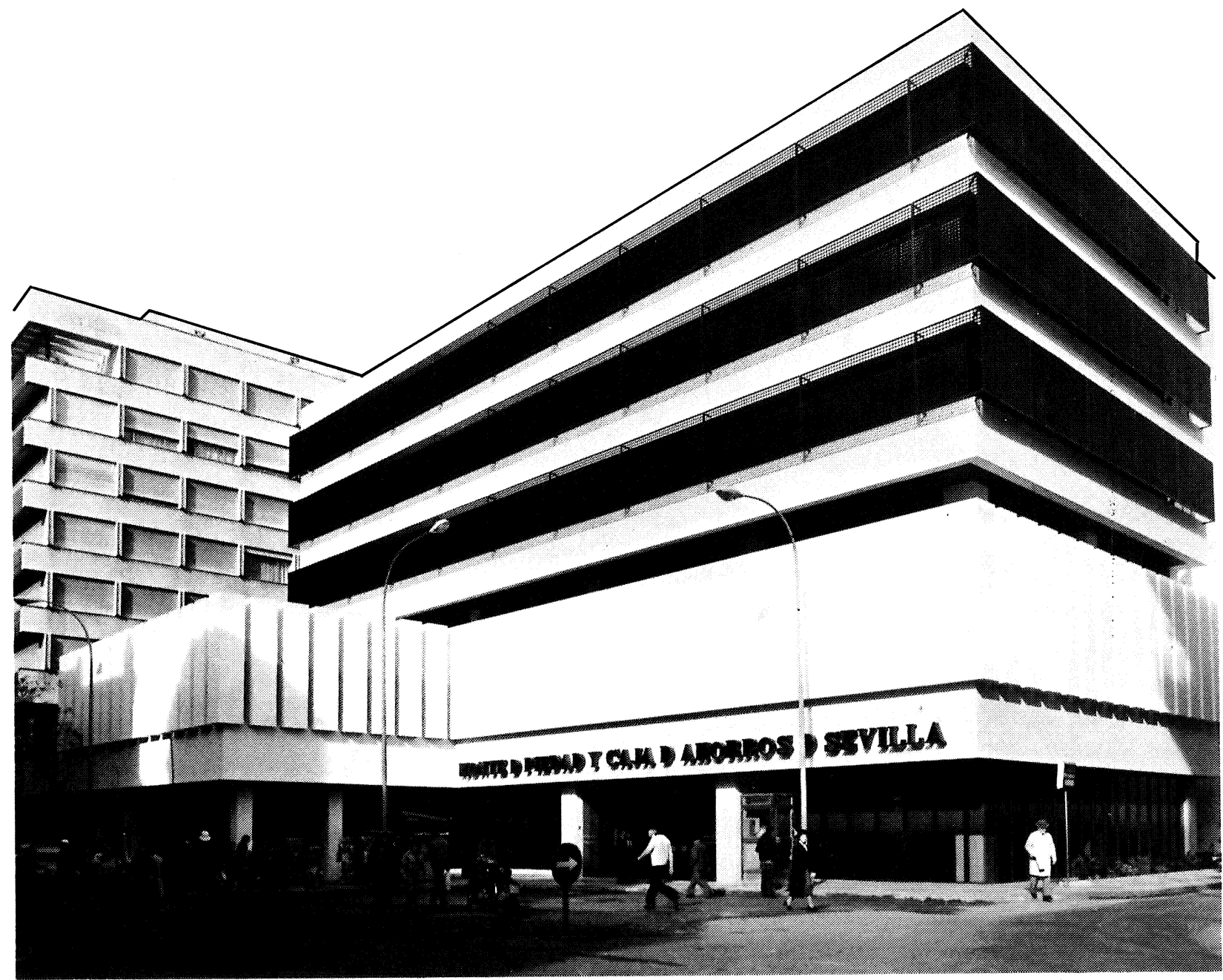


La nueva construcción del Monte de Piedad y Caja de Ahorros de Sevilla se ha levantado en un solar con forma de "L", de unos $1.500 \mathrm{~m}^{2}$ de superficie, emplazado en el centro de la ciudad, rodeado de edificios entre los que predomina la arquitectura típica sevillana, cuyos invariantes respeta el proyecto intentando incorporarlos dentro de un lenguaje actual.

El diseño, que ha sufrido sucesivas e importantes modificaciones desde que la entidad convocara un concurso nacional de anteproyectos en 1959, responde a dos condicionantes principales:
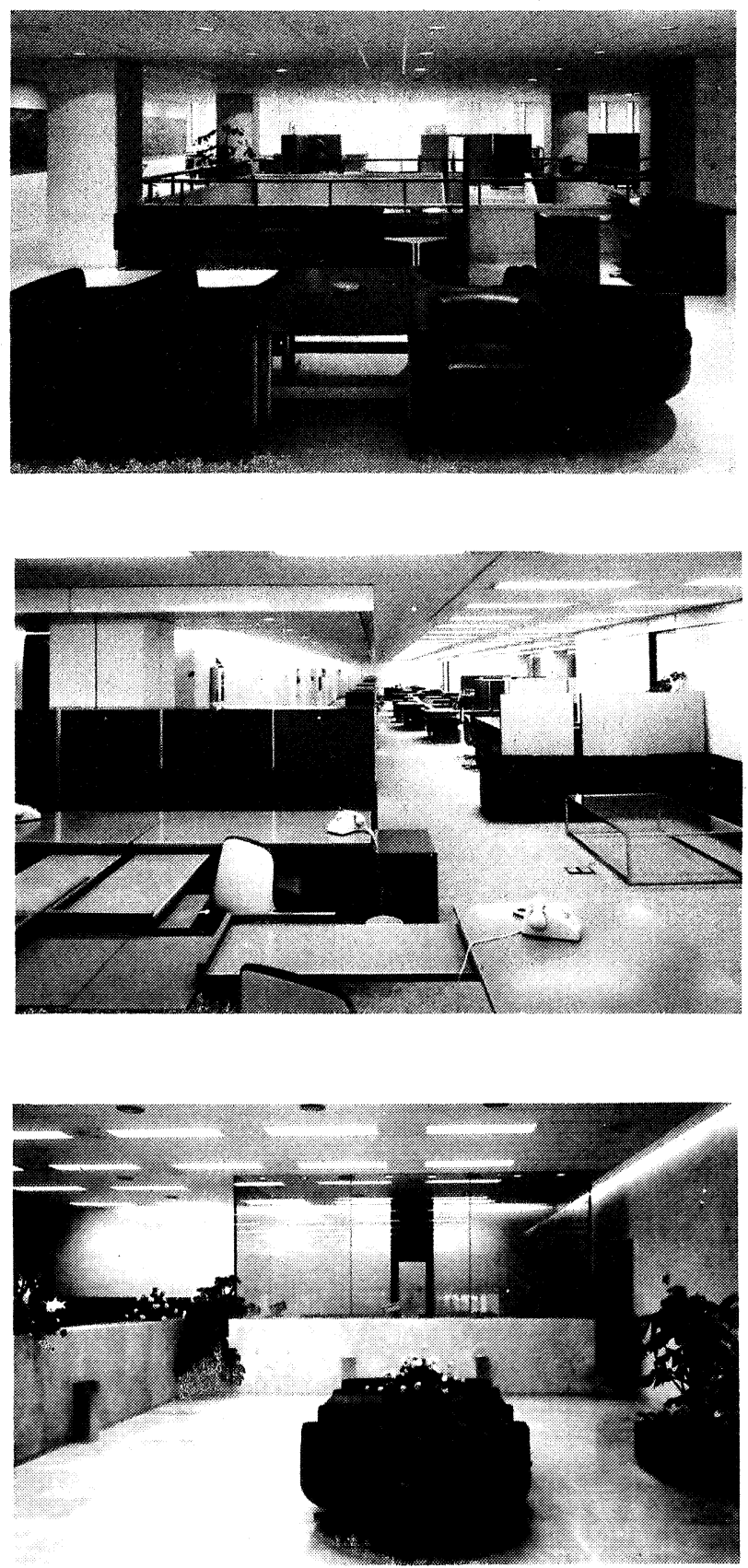

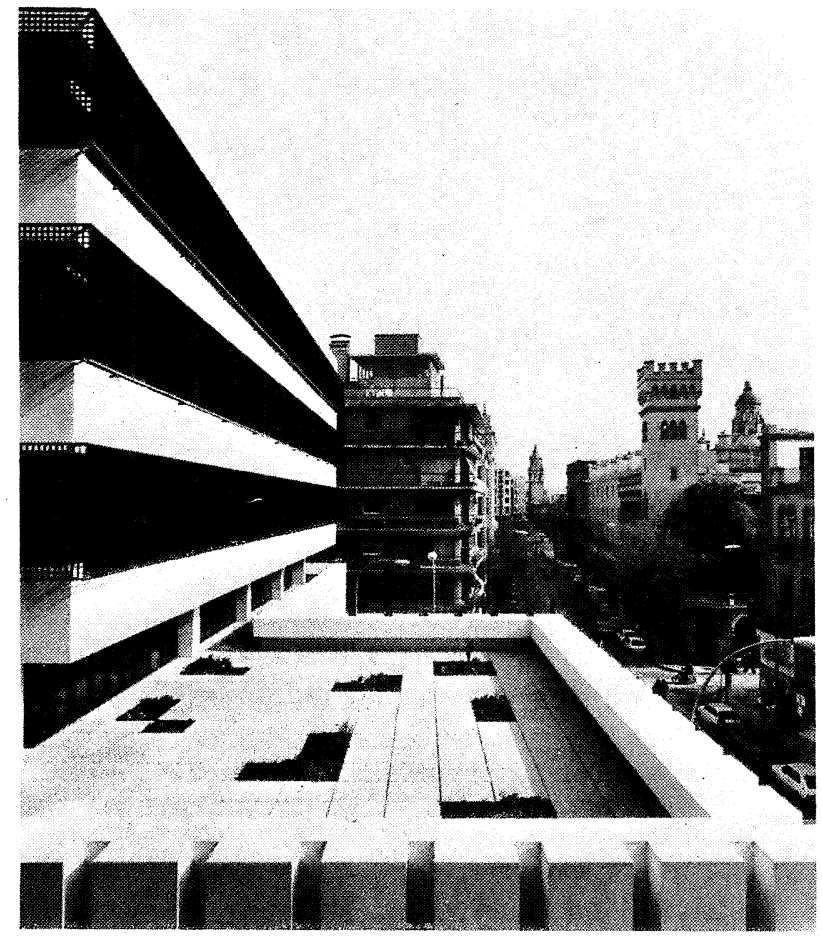

exterior

- adaptarse a las envolventes y perfiles de la edificación autorizados en las anteriores licencias, con las modificaciones necesarias para que se cumplan las nuevas Ordenanzas de Edificación del Casco Urbano -que no existian en aquella época-; y

- cubrir las áreas y programas establecidos conjuntamente por la propiedad y el autor en el estudio de planificación interna.

La construcción consta de dos sótanos que suman poco más de $2.800 \mathrm{~m}^{2}$ de superficie y siete plantas sobre rasante con un total de casi 6.600 metros cuadrados construidos.

De acuerdo con el programa, en los sótanos se han situado - además del garaje organizado en los dos niveles - el archivo, las cajas fuertes y los locales de máquinas. La planta baja -eminentemente pública - alberga las zonas de información y recepción, diversas oficinas y el salón de actos. La planta primera - continuación de la baja en su función de atender al cliente- distribuye las salas de convenciones y banquetes, más diversas oficinas. En la planta segunda se desarrollan distintos locales de presidencia y dirección. Por último, en las tres plantas superiores se han organizado las oficinas de la entidad. 


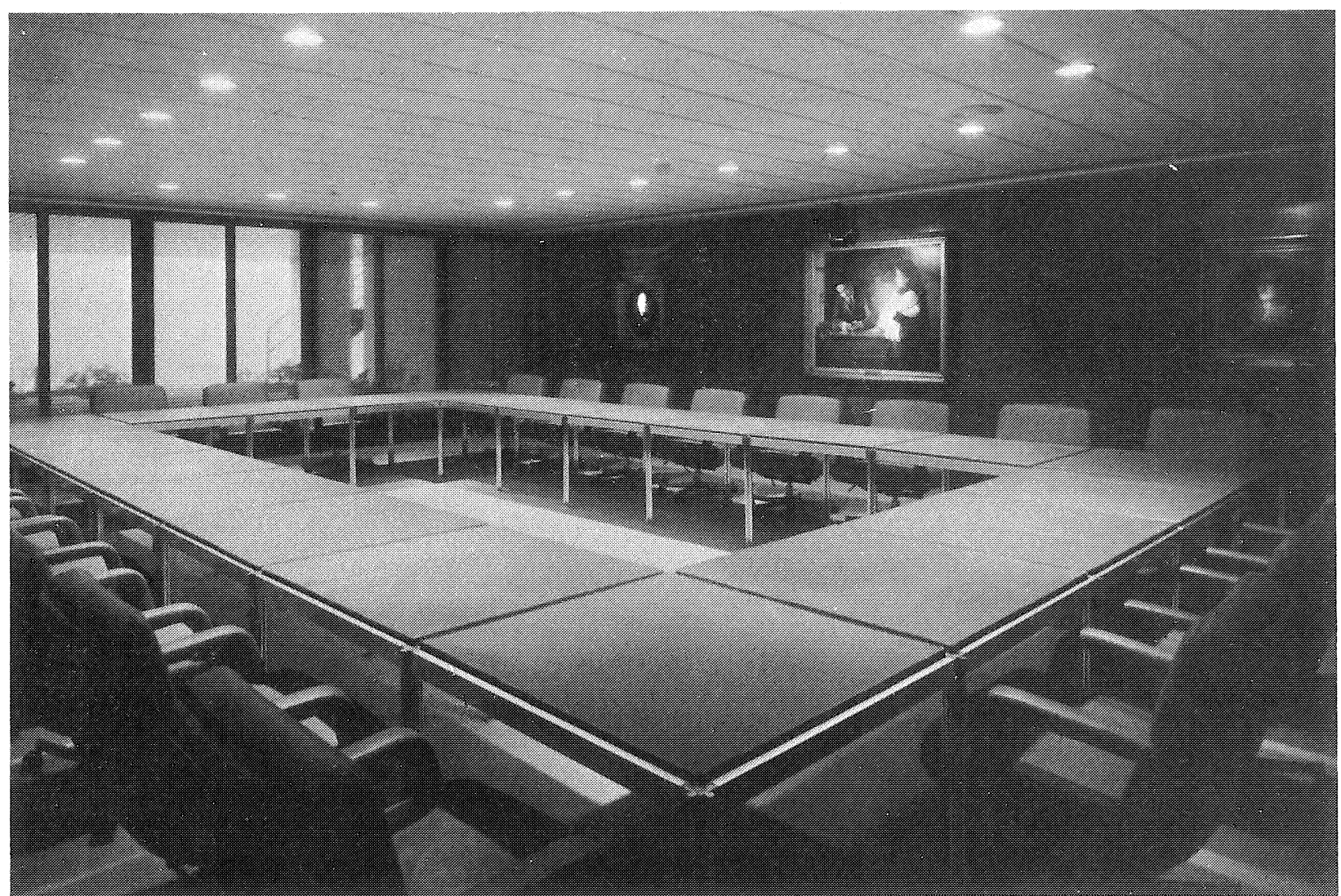

sala de consejo

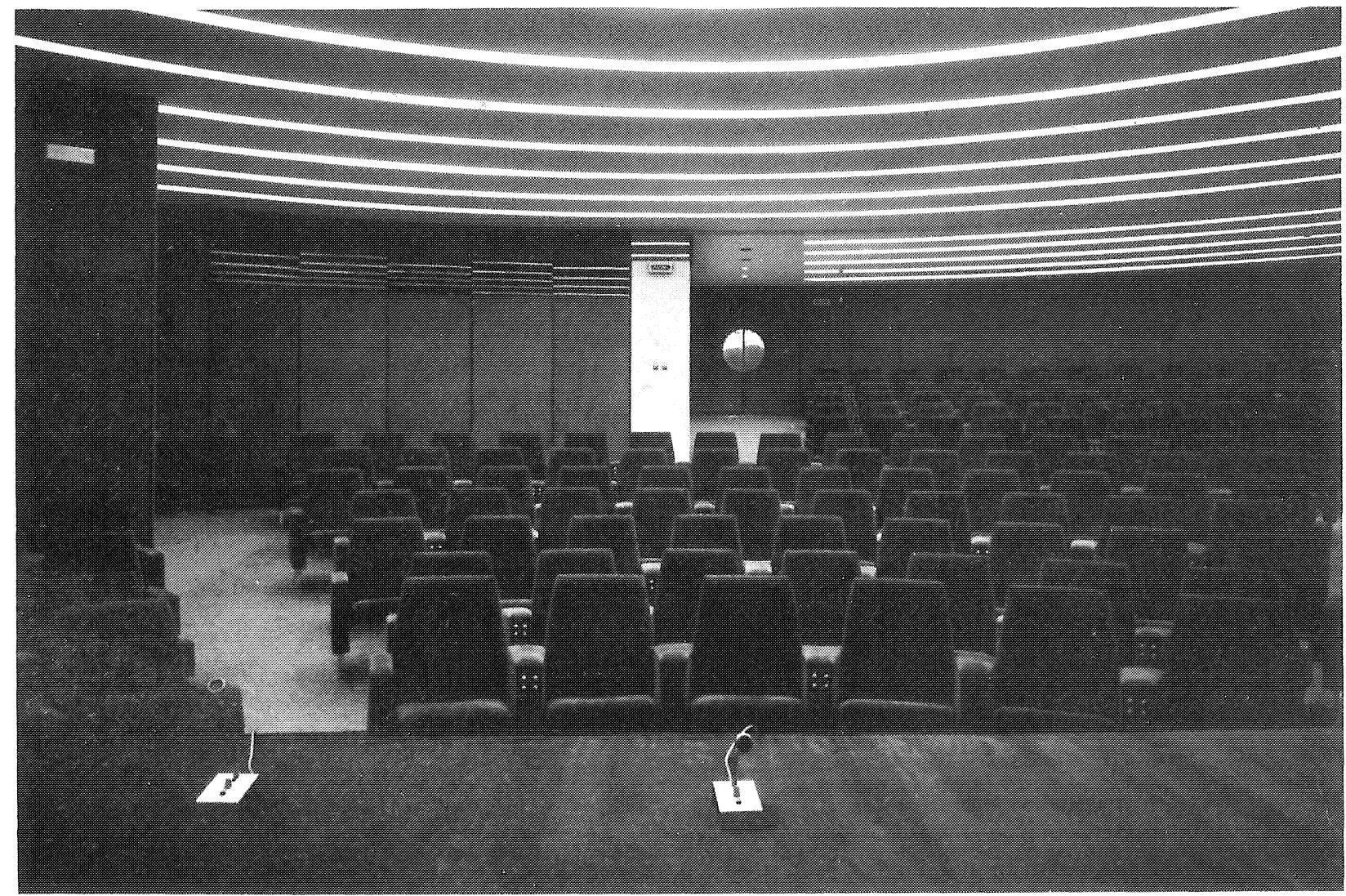



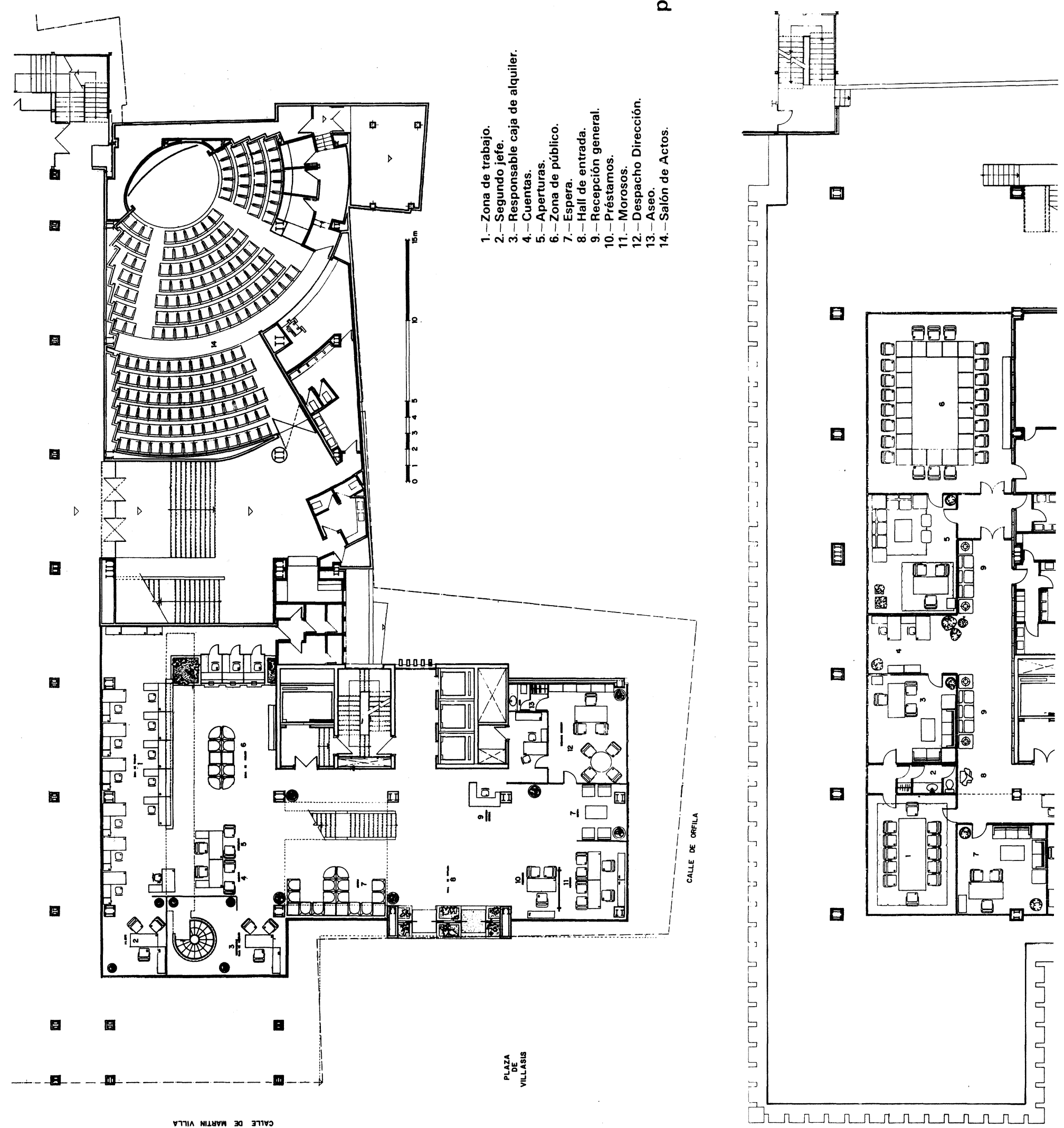


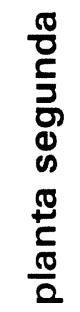

$\mathrm{I}^{\mathrm{E}}$

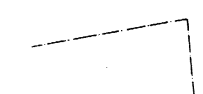

is

T.
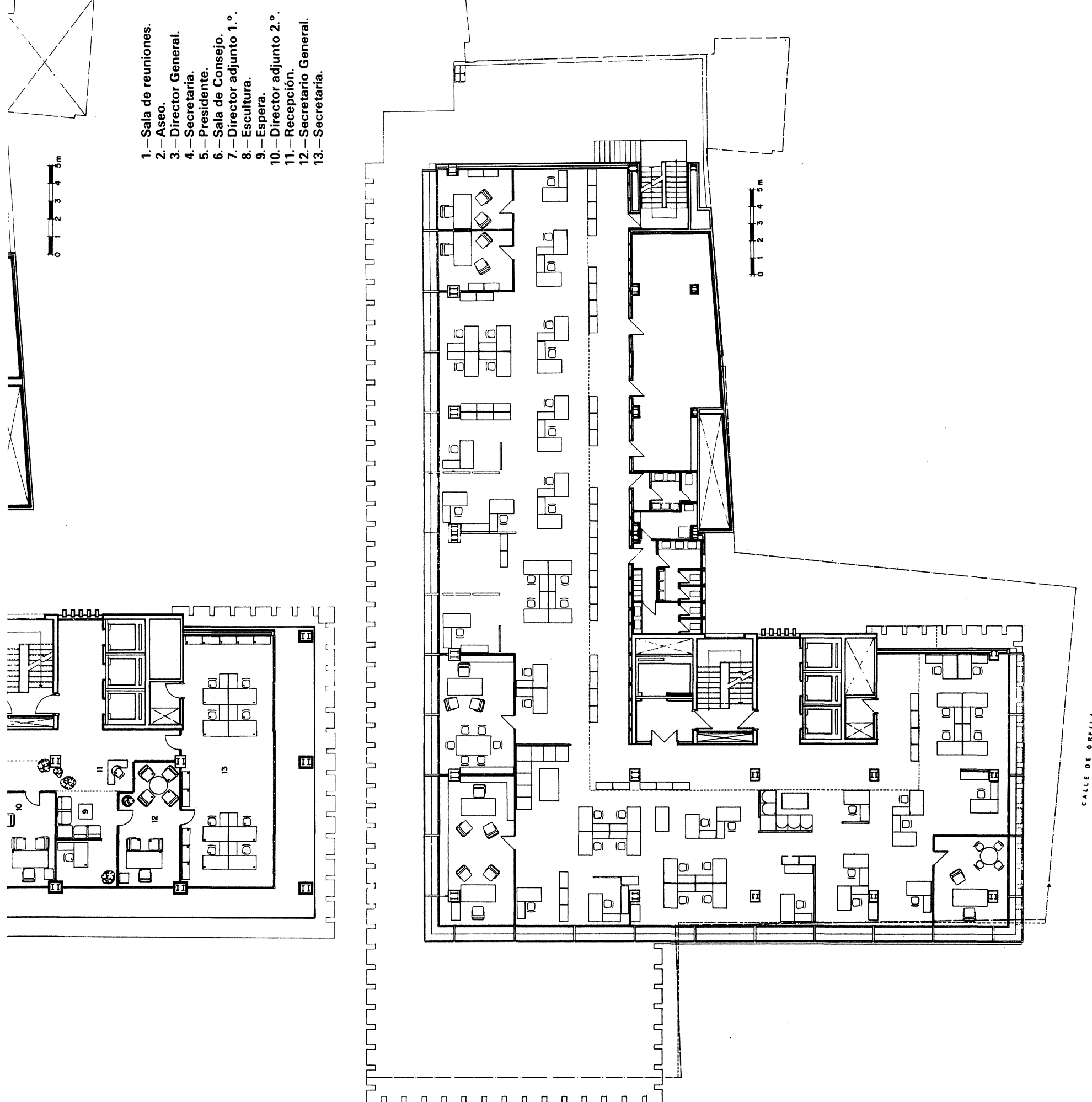


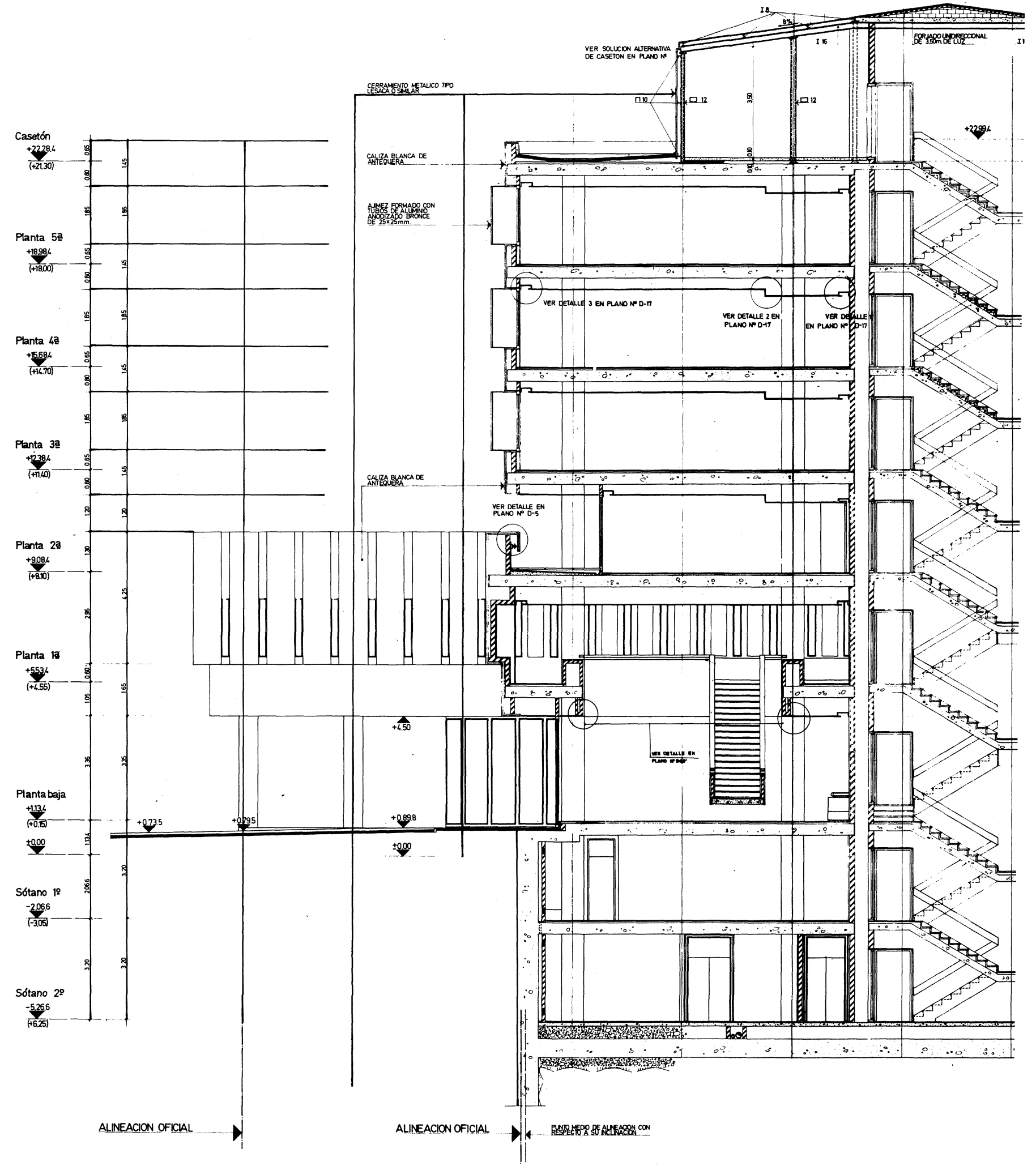




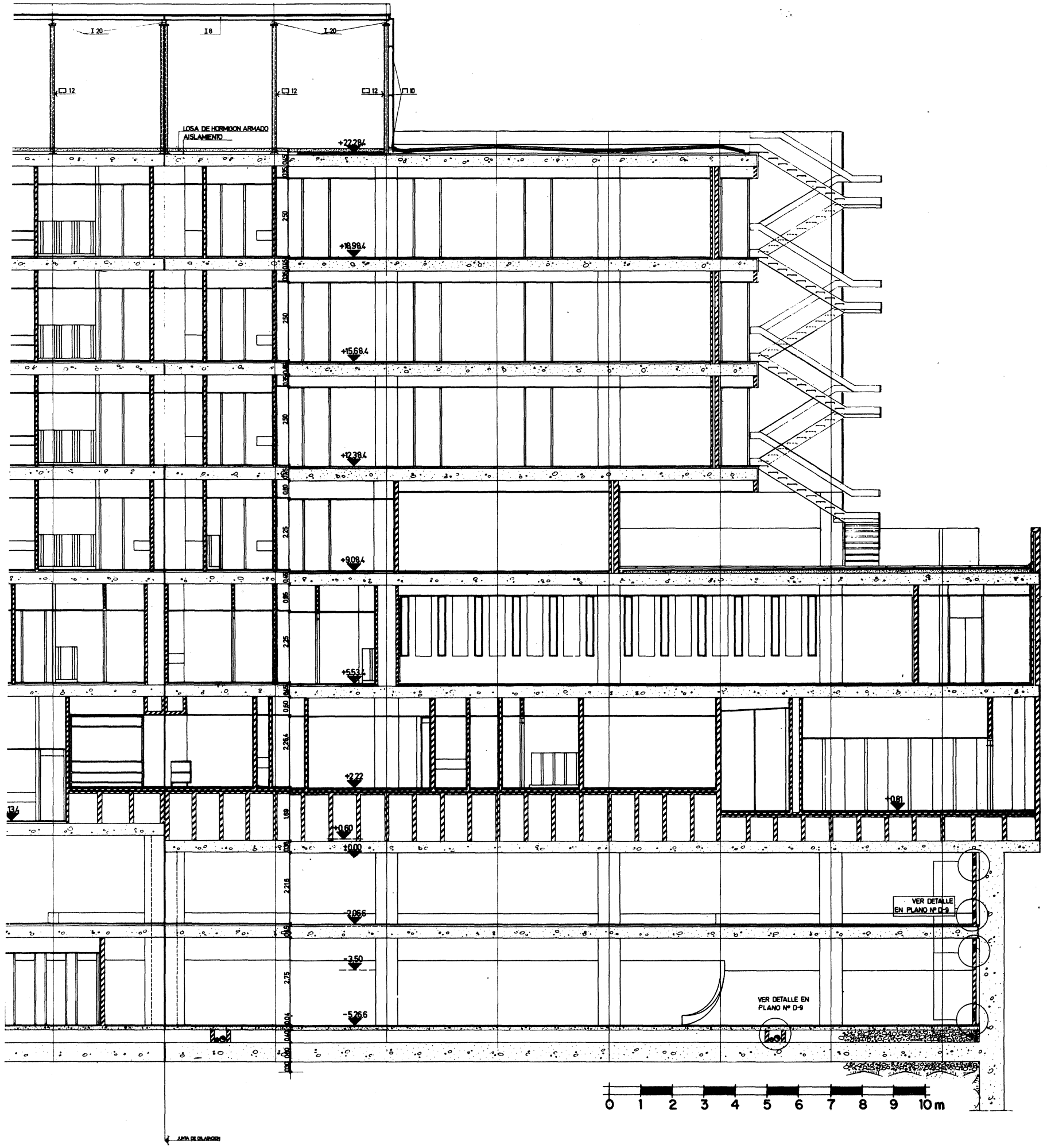


Arquitectónicamente el edificio se caracteriza por la diferenciación clara en forma, volumen y tratamiento exterior entre las plantas destinadas al contacto con el público y las que se dedican íntegramente al trabajo burocrático. A la separación de estos dos cuerpos contribuye también la planta segunda, acristalada en su totalidad y fuertemente retranqueada con relación a las restantes plantas proporcionando unas amplias terrazas a las zonas de presidencia y dirección.

La planta tipo de oficinas se presenta sin distribución alguna, totalmente diáfana, ya que al ser planteada como planta modular se puede organizar en ella cualquier distribución mediante tabiques móviles. Unicamente el núcleo central de comunicaciones, los accesos y servicios de planta se mantienen a lo largo de toda la altura del edificio.

Como protección del fuerte sol sevillano y de los ruidos exteriores se han dispuesto, por delante de las ventanas del cuerpo destinado a oficinas, unas celosias exteriores separadas del cerramiento que, por su forma, función y proporciones, recuerdan alguna de las características típicas de la arquitectura andaluza de otros tiempos.
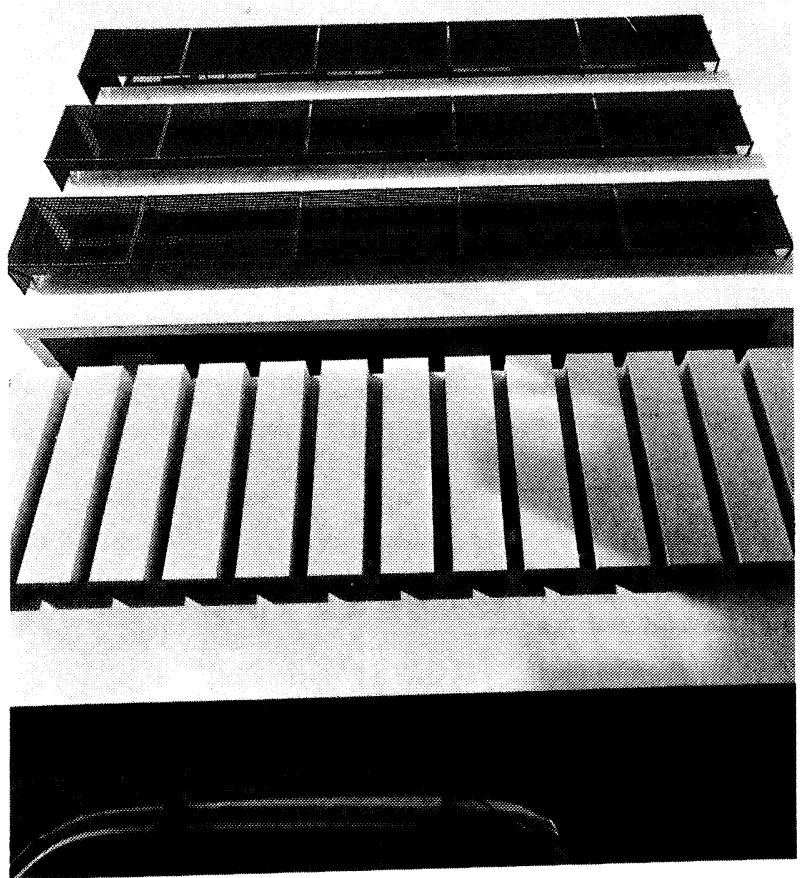

Fotos: COPIAFILM INDUSTRIAL

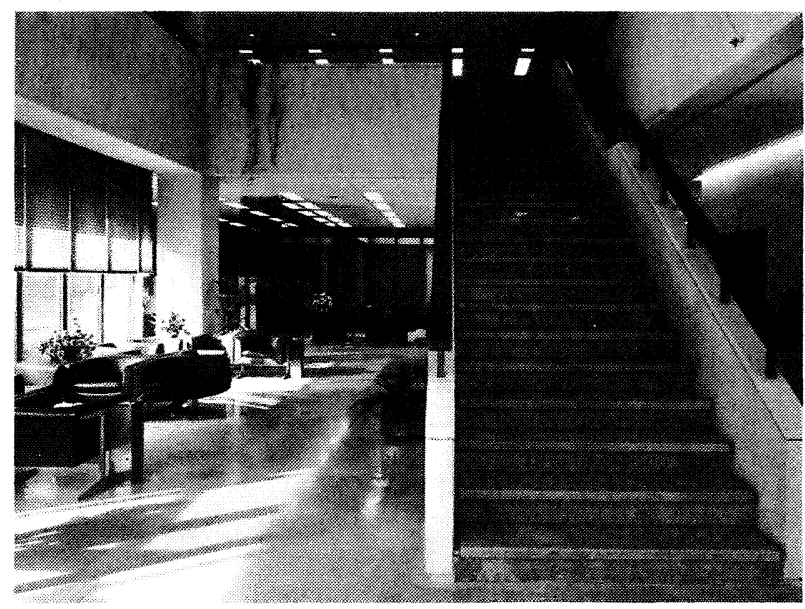

escalera

La planta primera, por el contrario, se cierra con cuerpos modulares de piedra blanca de Antequera.

Para la construcción se ha utilizado una estructura compuesta de losa de hormigón armado en dos direcciones, pilares metálicos y un núcleo central formado por pantallas de hormigón que absorbe la totalidad de los esfuerzos horizontales.

Por las grandes cargas del edificio, principalmente, se optó por una cimentación a base de pilotes encepados en cabeza.

Respecto al vaciado de los dos niveles de sótano, debido a una serie de condicionantes de solar y de proyecto, se recurrió a un proceso contrario al tradicional, que en este caso hubiera requerido una ejecución por fases resultando lento y difícil además de costoso. Dicho proceso consistió en realizar primero una pantalla continua de hormigón armado mediante lodos bentoníticos para, posteriormente, proceder al vaciado del solar, lo cual pudo hacerse con medios mecánicos en su totalidad.

\section{exterior}

